\section{International Scientific Journal Theoretical \& Applied Science}

\author{
Valeriy Mykhailovich Speshylov \\ Senior Lecturer of Naval Polytechnic Institute, \\ Russian Federation \\ Viktoriia Viktorovna Kulinich \\ Postgraduate student, Assistant of the Department of \\ Navigation \\ Kherson State Maritime Academy, \\ Ukraine \\ victorystep@ list.ru
}

SECTION 27. Transport.

\title{
THE NAVIGATION SAFETY CONCEPT IN THE CONTEXT OF THE CONVENTION ON INTERNATIONAL REGULATIONS FOR PREVENTING COLLISIONS AT SEA
}

\begin{abstract}
The complex of the Convention on International Regulations for Preventing Collisions at sea (COLREG-72) fundamentals, which determines system of measures and actions for safe ships passing at sea, was researched. The reasons of navigators uncoordinated actions during ships passing with safe distance at sea were analyzed. Quantitative and qualitative characteristics definition of some uncertain concepts in COLREG-72 was proposed. Initial data's range for algorithm's output of collisions prevention actions sequence was considered.

Key words: Safety of navigation, narrow channel, sufficient sea room, close-quarter situation.

Language: Russian

Citation: Speshylov VM, Kulinich VV (2016) THE NAVIGATION SAFETY CONCEPT IN THE CONTEXT OF THE CONVENTION ON INTERNATIONAL REGULATIONS FOR PREVENTING COLLISIONS AT SEA. ISJ Theoretical \& Applied Science, 07 (39): 40-51.

Soi: http://s-o-i.org/1.1/TAS-07-39-8 Doi: crossef http://dx.doi.org/10.15863/TAS.2016.07.39.8
\end{abstract}

\section{КОНЦЕПЦИЯ БЕЗОПАСНОСТИ МОРЕПЛАВАНИЯ В КОНТЕКСТЕ КОНВЕНЦИИ О МЕЖДУНАРОДНЫХ ПРАВИЛАХ ПРЕДУПРЕЖДЕНИЯ СТОЛКНОВЕНИЯ СУДОВ}

Аннотация: Проведено исследование комплекса ключевых положений Международных правил предупреждения столкновения судов (МППСС-72), определяющего систему мер и действий по обеспечению безопасного расхождения судов в море. Произведен анализ причин несогласованности действий судоводителей по расхождению судов на безопасном расстоянии. Предложена мотивация количественных и качественных характеристик положений МППСС-72, имеющих неопределенный характер. Рассмотрен диапазон исходных данных для выработки алгоритма действий, предпринимаемых для предупреждения столкновения судов.

Ключевые слова: Безопасность мореплавания, узкость, достаточное водное пространство, чрезмерное сближение судов.

\section{1. Введение}

Безопасность мореплавания в контексте Конвенции о Международных правилах предупреждения столкновения судов (далее Конвенция о МППСС-72) - это расхождение сближающихся судов на безопасном расстоянии, успех которого в значительной степени зависит от согласованности действий этих судов по единым Правилам предупреждения столкновения судов (далее - Правила ПСС), установленным данной Конвенцией. На практике же нередки случаи, когда одни и те же Правила ПСС трактуются судоводителями по-разному $[1,2,3]$. Одной из основных причин разночтения Правил ПСС является неопределенность и

ISPC Results and Perspectives,

Harrisburg, USA неоднозначность таких понятий в контексте МППСС-72, как узкость (Правило 9), достаточное водное пространство [Правило 8 (c)], чрезмерное сближение судов [Правила 8 (c), 9 (c) и 19 (d)], расхождение судов на безопасном расстоянии [Правило 8 (d)], своевременные и уверенные действия для предупреждения столкновения судов [Правило 8 (d)], ограниченная видимость (Правила 19 и 35) [4, 5]. Определение количественной и качественной характеристики вышеперечисленных понятий в контексте МППСС-72 создает предпосылки к выработке алгоритма действий для предупреждения столкновения судов, который позволяет оперативно и грамотно принимать решение на 
маневр судна курсом и (или) скоростью с учетом того, что исходные данные для принятия такого решения могут изменяться в определенных пределах.

\section{2. Анализ литературных данных и постановка проблемы}

Анализ публикации на тему «Комментарии к МППСС-72» [6] показывает, что попытки определения численных и качественных характеристик таких понятий, как узкость, чрезмерное сближение, своевременные действия для предупреждения столкновения, не прекращаются. Определение понятия «узкость» в комментарии к Правилу 9 основано на судебных прецедентах по делам столкновения судов, которые, однако, не дают однозначной трактовки этого понятия: по результатам одних судебных решений узким проходом признавался проход шириной 2 мили, а по результатам других судебных решений - проход шириной 1.2 миль не был признан узким. В комментарии к Правилу 19 сделан вывод о том, что «конкретное расстояние, на котором впервые возникает ситуация чрезмерного сближения, не было и, вероятно, не будет определено». Тем не менее, в этом же Комментарии дана мотивация определения численной характеристики чрезмерного сближения в условиях ограниченной видимости в открытом море: 2 мили - расстояние слышимости свистка большого судна и 3 мили с учетом возможных ошибок радиолокационного наблюдения судна цели на больших дистанциях. В комментарии к Правилу 17 без какой-либо мотивации дана рекомендация не допускать сближения с другим судном на дистанцию менее двенадцатикратной длины собственного судна, если суда идут пересекающимися курсами на виду друг у друга и при этом собственное судно согласно Правилу 17 имеет статус судна, которому уступают дорогу. Двенадцатикратный размер собственного судна не может быть признан универсальным критерием чрезмерного сближения судов, так как при длине собственного судна 200 $\div 400$ метров - дистанцию кратчайшего сближения в диапазоне $1.3-2.5$ миль далеко не всегда можно использовать в качестве критерия чрезмерного сближения при плавании в стесненных водах. В комментарии к Правилу 19 предлагается ничем не обоснованные ориентиры своевременных действий для предупреждения столкновения судов:

- зона оценки ситуации сближения на удалении от своего судна в диапазоне 8-12 миль;

- зона действий для предупреждения столкновений на удалении от своего судна в диапазоне 4-8 миль.

В главе 13 издания [7, с. 510] изложено понятие о потенциально опасной цели, ситуация сближения с которой не вызывает необходимости выполнения маневра расхождения с этой целью на безопасном расстоянии. Однако при определенном изменении ситуации сближения потенциальная опасность может перерасти в реальную угрозу столкновения и в конечном итоге угроза столкновения может стать реализованной. Анализ условий возникновения потенциальной, реальной и реализованной угрозы столкновения в этом и других изданиях и публикациях не производился, тогда как этот анализ необходим для определения характера действий по выполнению маневра расхождения, который в зависимости от вероятности столкновения подразделяется на 2 последовательных этапа:

действия для предотвращения возникновения опасности столкновения при наличии потенциальной угрозы столкновения и при наличии реальной угрозы столкновения на ранней стадии сближения;

- действия для избежания столкновения при возникновении опасности столкновения.

Маневры для избежания столкновения изложены в публикации [6, с. 288], однако в данной редакции допущено смешивание этого понятия с понятием маневра для предотвращения возникновения опасности столкновения.

Определение конкретных и обоснованных количественных и качественных характеристик таких понятий, как узкость, чрезмерное сближение, своевременные и уверенные действия для предупреждения столкновения, ограниченная видимость в районе плавания обусловлено необходимостью создания определенного диапазона исходных данных для выработки алгоритма действий по безопасному расхождению судов.

\section{3. Цель и задачи исследования}

Целью исследования является формулировка концепции безопасности мореплавания в контексте Конвенции о МППСС-72 и представление ее в виде, удобном для выработки алгоритма действий по безопасному расхождению судов.

Для достижения поставленной цели решались следующие задачи:

- определить основные этапы действий судов по обеспечению безопасного расхождения;

- внести определенность в такие понятия как узкость, достаточное для маневрирования курсом водное пространство, чрезмерное сближение судов, расхождение судов на безопасном расстоянии, своевременные и уверенные действия для предупреждения столкновения судов. 


\section{результатов}

4.1. Определение количественной и качественной характеристики положений МППСС-72, имеющих неопрделенный характер

Концепцией безопасности мореплавания в контексте Конвенции о МППСС-72 является комплекс ключевых положений Международных правил предупреждения столкновения судов, позволяющий определять систему мер и действий по обеспечению безопасного расхождения судов в море. Для упорядочения применения Правил ПСС - действия судов по обеспечению безопасного расхождения целесообразно разделить на 2 этапа:

- действия первого этапа предпринимаются на ранней стадии развития ситуации сближения для предотвращения возникновения опасности столкновения, которые регламентируются Правилами 8, 9, 10 Раздела I, Правилами 18 (d) (l), 18 (d) (ii), 18 (e) Раздела II, Правилами 19 (a), 19 (b), 19 (c) и 19 (d) Раздела III МППСС-72.

- действия второго этапа предпринимаются при возникновении опасности столкновения для избежания прямого столкновения или для минимизации последствий неизбежного столкновения, которые регламентируются Правилом 8 (c) Раздела I, Правилами 11-17, 18 (a), 18 (b), 18 (е) Раздела II и правила 19 (е) Раздела III Части В МППСС-72.

Порядок применения Правил ПСС для предотвращения возникновения опасности столкновения зависит от стесненности района плавания, вероятности угрозы столкновения и от условий метеорологической видимости в районе плавания.

Критерием стесненности района плавания является соотношение между маневренными характеристиками судна с учетом его линейных размеров и ширины акватории, в пределах которой судно может следовать безопасно при существующих средствах навигационного обеспечения. В зависимости от критерия стесненности - район плавания можно условно разделить на следующие категории в контексте МППСС-72: узкость, полоса движения в системе разделения движения и водное пространство, достаточное для маневрирования курсом.

Узкость - это такая акватория, на которой возможность судна маневрировать курсом ограничена близостью берега, подводных и надводных скал (камней, кораллов и пр.), рельефом морского дна (несудоходными глубинами, банками и пр.), расположенными справа и слева от линии пути судна. Таким образом, критерием узкости в контексте МППСС-72 является ширина судоходной зоны акватории - кратчайшее расстояние между изобатами, соединяющими минимальнодопустимые для плавания глубины моря справа и слева от линии пути судна: если ширина судоходной зоны менее диаметра циркуляции судна, то маневрирование этого судна курсом на этой акватории ограничено и поэтому этот проход для данного судна является узким. Исходя из хорошей морской практики - диаметр циркуляции судна принимается равным восьмикратной длине судна [7, с. 302; 8, с. 135], а минимальный запас глубины моря под килем принимается равным одной трети осадки этого судна. Таким образом, ширина судоходной части прохода $\amalg_{\text {пр }}=\mathrm{D}_{\text {ц }}=8 \mathrm{~L}$, а минимально допустимая глубина в узком проходе $\mathrm{H}_{\min }=1.3 \mathrm{~d}$. Однако понятие узкости для отдельно взятого судна не приемлемо для применения Правила 9 МППСС72, так как положения этого Правила определяют взаимные обязанности всех судов на отдельно взятой акватории, которая для крупных судов может быть признана узкостью, а для других судов с меньшими линейными размерами узкостью не считается. Для достижения согласованных действий по единым для всех судов Правилам ПСС - ширину судоходной зоны целесообразно оценивать исходя из линейных размеров наиболее крупных судов супертанкеров и контейнеровозов, длина которых достигает 400 метров и осадка - 25 метров у супертанкеров и 12 метров у контейнеровозов (по состоянию на 2013 год все супертанкеры длиной более 400 метров выведены из эксплуатации). С учетом того, что супертанкеры с осадкой более 12-ти метров исчисляются в Мировом флоте единицами - за основу определения ширины судоходной зоны прохода можно брать длину условного судна 400 метров с осадкой 12 метров $\left(\amalg_{\text {пр }}=\mathrm{D}_{\text {ц }}=8 \mathrm{~L}=8 \times 400=3200\right.$ м $\approx 2$ мили, $\left.\mathrm{H}_{\min }=1.3 \mathrm{~d}=1.3 \times 12 \approx 15 \mathrm{м}\right)$. Таким образом, если кратчайшее расстояние между 15-ти метровыми изобатами узкости с учетом банок и других подводных препятствий менее 2-х миль, то этот проход в контексте МППСС-72 предлагается считать узким проходом (узкостью).

Водное пространство, достаточное для маневрирования курсом, - это акватория моря с шириной судоходной зоны более 2-х миль.

В контексте МППСС-72 водное пространство, достаточное для маневрирования курсом, принято называть открытым морем.

Вероятность возникновения опасностей изучает наука о безопасности жизнедеятельности, которая оперирует такими понятиями, как потенциальная, реальная и реализованная опасности $[9,10]$. Исходя из теории вероятности, потенциально опасными в плане столкновения являются все суда, находящиеся на ходу, независимо от общей величины изменения 
пеленга (ОВИП) и общей величины изменения расстояния (ОВИР), так как нельзя исключать опасного сближения с судном сателлитом или с судном, расстояние до которого увеличивается, если эти суда начнут маневрировать курсом и (или) скоростью. Поэтому во исполнение Правил 7 (b) и 7 (c) МППСС-72 необходимо вести радиолокационную прокладку или равноценное систематическое наблюдение за каждым обнаруженным объектом с целью получения полной радиолокационной информации о нем условия расхождения с судном целью и его параметры движения. Реальная угроза столкновения с судном целью возникает в том случае, когда развивается ситуация чрезмерного сближения с этим судном. Для определения количественной характеристики чрезмерного сближения предлагается качественную характеристику этого понятия определять в зависимости от стесненности района плавания. Если плавание происходит в районе открытого моря, то чрезмерным сближением с судном целью является такое кратчайшее расстояние сближения с этим судном, при котором возможна потеря контроля за развитием ситуации сближения в случае неблагоприятного маневрирования судна цели [7]. Исходя из широкого диапазона понятия «неблагоприятное маневрирование судна цели» предлагается ограничиться наиболее сложной ситуацией, когда судно цель ложится на вынужденную циркуляцию с неисправным рулевым устройством. Поэтому сближение судов в районе открытого моря предлагается считать чрезмерным, если кратчайшая дистанция сближения с судном целью равна диаметру циркуляции этого судна и менее. Поскольку диаметр циркуляции судна определяется восьмикратной длиной его корпуса, то количественную характеристику понятия чрезмерного сближения можно определить по длине судна цели, которая указана в статической информации автоматической идентификационной системы (АИС). Если ситуация осложняется одновременным сближением трех или более судов, то для единого подхода к понятию чрезмерного сближения со всеми судами целесообразно исходить из длины корпуса наиболее крупного из числа сближающихся судов. Если же длину какоголибо судна с помощью АИС определить невозможно, то для количественной оценки чрезмерного сближения целесообразно принимать длину условного судна 400 м. С учетом возможных ошибок радиолокационного наблюдения на дистанции 12 миль - безопасным для расхождения расстоянием $\left(\mathrm{S}_{\text {без }}\right)$ в открытом море при полной дневной видимости целесообразно считать $\mathrm{S}_{\text {без }}=8 \mathrm{~L}_{\text {сц }}+1$ миля. Для повышения оперативности принятия решения на маневр предлагается следующий способ определения $\mathrm{S}_{\text {без }}$ : $\mathrm{L}_{\text {сц }}=20-50$ м $\mathrm{S}_{\text {без }}=1$ миля; $\mathrm{L}_{\text {сц }}$ $=50-150 \mathrm{м} \mathrm{S}_{\text {без }}=1,5$ миль; $\mathrm{L}_{\text {сц }}=150-250 \mathrm{м} \mathrm{S}_{\text {без }}=$ 2 мили; $\mathrm{L}_{\text {сц }}=250-350$ м $\mathrm{S}_{\text {без }}=2,5$ миль; $\mathrm{L}_{\text {сц }}=350$ 400 м $\mathrm{S}_{\text {без }}=3$ мили.

Наиболее эффективным действием для предупреждения чрезмерного сближения в районе плавания с достаточным водным пространством является маневр курсом, продолжительность которого намного меньше маневра скоростью. Несомненным достоинством маневра курсом является то, что при плавании в открытом море судовая силовая установка длительное время работает в устоявшемся режиме экономического хода, нарушение которого для выполнения маневра скоростью крайне нежелательно с точки зрения надежности силовой установки и экономии топлива. Необходимость маневра скоростью может возникнуть при невозможности выполнения маневра курсом для предупреждения чрезмерного сближения с судном целью, если, например, изменение курса вызывает чрезмерное сближение с другими судами. Исходя из требования Правила 6 МППСС-72 - маневр скоростью обычно выполняется в сторону уменьшения скорости хода судна в том числе и для того, чтобы иметь больше времени для оценки ситуации сближения с судами.

Согласно Правилам 8 (a) и 8 (c) МППСС-72 действия для предупреждения чрезмерного сближения должны быть уверенными, своевременными и заблаговременными. При этом понятие «уверенные действия» нередко подменяется понятием «решительные действия», которые согласно Правилу 8 (b) МППСС-72 трактуются как достаточно большое изменение курса и (или) скорости судна, предпринимаемые для предупреждения столкновения судов. Ряд последовательных небольших изменений курса и (или) скорости судна в контексте Правила 8 (b) являются нерешительными действиями, которые на практике отождествляются с неуверенными действиями, тогда как неуверенность в правильности предпринимаемых действий возникает в том случае, когда радиолокационная информация о судне цели неполная и недостоверная. Полноту радиолокационной информации о судне цели определяют вычисленные посредством ручной или автоматической радиолокационной прокладки условия расхождения с этим судном и его параметры движения: дистанция кратчайшего сближения с судном целью ( $\left.D_{\text {кр }}\right)$ и время сближения на эту кратчайшую дистанцию $\left(\mathrm{t}_{\mathrm{kp}}\right)$, a также истинные курс и скорость судна цели $\left(\mathrm{K}_{ц}\right.$ и

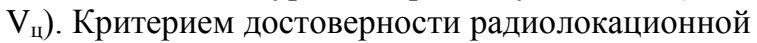
информации о судне цели является точность 
вычисления $\mathrm{D}_{\text {кр }}, \mathrm{t}_{\text {кр }}, \mathrm{K}_{\text {ц }}$ и $\mathrm{V}_{\text {ц. }}$ Величину допустимой погрешности вычисления этих параметров определяет Резолюция А.422 (XI) 1979 г ИМО. Наибольшее влияние на величину погрешности вычисления $\mathrm{D}_{\text {кр }}, \mathrm{t}_{\text {кр }}, \mathrm{K}_{\text {ц }}$ и $\mathrm{V}_{\text {ц }}$ оказывает погрешность измерения полярных координат судна цели, величина которой находится в прямой зависимости от дистанции до этого судна на момент измерения его координат. Расчетно-опытным путем установлено, что на расстоянии до судна 12 миль и менее погрешность измерения пеленга и расстояния до этого судна допустима для вычисления $\mathrm{D}_{\text {кр }}, \mathrm{t}_{\mathrm{kp}}, \mathrm{K}_{\mathrm{L}}$ и $\mathrm{V}_{\text {ц }}$ с достаточной точностью.

4.2 Исследование порядка действий для предупреждения столкновения судов В открытом море

Своевременные и заблаговременные действия для предупреждения чрезмерного сближения с судном целью в открытом море предполагают измерение полярных координат судна цели для получения радиолокационной информации об этом судне на ранней стадии сближения по принципу «чем раньше, тем лучше». Если эхо-сигнал обнаружен на удалении более 12-ти миль, то для получения достоверной радиолокационной информации о судне цели измерение его полярных координат необходимо производить в момент сближения с ним на расстояние 12 миль - не ранее. Если развивается ситуация чрезмерного сближения, то маневр своего судна для предотвращения возникновения опасности столкновения должен начаться не позднее, чем через 6 минут после начала измерения полярных координат судна цели, так как время запаздывания маневра на 6 минут обусловлено трехминутным непрерывным автоматическим сопровождением судна цели, необходимым для вычисления $\mathrm{D}_{\text {кр }}, \mathrm{t}_{\text {кр }}, \mathrm{K}_{\text {ц }}$ и $\mathrm{V}_{\text {ц }}$, и трехминутным промежутком времени, необходимым для оценки ситуации сближения судов и принятия решения на маневр своего судна. Поскольку за время запаздывания маневра 6 минут - ОВИР судов достигает наибольшего значения 5 миль при движении судов прямо друг на друга на скорости хода каждого из них 25 узлов, то действия судна для предотвращения чрезмерного сближения с судном целью в открытом море считаются своевременными и заблаговременными, если измерение полярных координат этого судна началось на расстоянии 12 миль, а маневр для предотвращения чрезмерного сближения начался на расстоянии не менее 7-ми миль до судна цели при условии, что эхо-сигнал этого судна обнаружен на удалении не менее 12 миль. При более позднем обнаружении эхосигнала возникает дефицит времени для оценки ситуации сближения и принятия решения на маневр, в результате чего может возникнуть необходимость снижения скорости хода собственного судна для увеличения этого времени. Поэтому для своевременного обнаружения эхо-сигнала при плавании в открытом море - внешнюю границу зоны автоматического захвата цели на экране САРП необходимо выставлять на удалении 12 миль с включением предупредительной световой и звуковой сигнализации.

Порядок маневрирования курсом для предотвращения чрезмерного сближения с судном целью в открытом море зависит от метеорологической видимости в районе плавания и от времени суток. Если суда находятся на виду друг у друга, то на первом этапе расхождения судов порядок маневрирования судна курсом для предотвращения чрезмерного сближения с судном целью Правилами МППСС-72 не регламентирован. Визуальная дальность видимости судна в светлое время суток зависит от прозрачности воздуха тропосферы и угловых размеров судна. Поскольку действия первого этапа по безопасному расхождению судов в открытом море должны начинаться на удалении судна цели 12 миль, то на таком расстоянии судно цель будет на виду, если коэффициент прозрачности воздуха тропосферы будет не менее 0.8 на милю ( $\tau \geq 0.8$ на милю), высота окон ходовой рубки своего судна над уровнем моря не менее 33 метра (е $\geq 33$ м) и высота надстроек судна цели над уровнем моря не менее 13 метров $\left(\mathrm{h}_{ц} \geq 13 \mathrm{M}\right)$ :

$$
\begin{aligned}
& e=\left(\frac{D}{2.08}\right)^{2}=\left(\frac{12}{2.08}\right)^{2}=33.3 \approx 33 \mathrm{M} \\
& h=\text { Darc }^{\prime}=\frac{12 \times 2^{\prime}}{3438^{\prime}}=0.0696 \text { миль } \approx 13 \mathrm{M},
\end{aligned}
$$

где $\gamma^{\prime}-$ угол зрения контура судна цели, угловые минуты в сексагиземальном делении.

В любом случае, при наличии ситуации чрезмерного сближения с судном целью судоводитель свободен в выборе маневра курсом для предотвращения возникновения опасности столкновения, если в момент принятия решения на маневр - судно цель окажется на виду. В противном случае, когда наблюдение за судном целью ведется только с помощью радара, порядок маневрирования курсом для предотвращения чрезмерного сближения с этим судном предусмотрен Правилами 19 (d), 19 (d) (i) и 19 (d) (ii) МППСС-72, действия которых прекращаются в момент визуального обнаружения силуэта судна цели.

В темное время суток визуальная дальность видимости судна цели зависит от прозрачности воздуха тропосферы, а также от силы света и контрастности ходовых отличительных огней судна цели. В условиях полной ночной метеорологической видимости $(\tau=0.8$ на милю) - 
визуальное обнаружение судна на расстоянии 12ти миль возможно, если сила света судовых огней не менее 1500 кандел ( $\geq 1500$ кд). Согласно Приложению I к МППСС-72 - во избежание чрезмерного ослепляющего действия - сила света судовых огней должна быть не более 94 кандел, которая обеспечивает визуальную видимость огня 6 миль, при коэффициенте прозрачности воздуха тропосферы $\tau \geq 0.8$ на милю.

Таким образом, при плавании в открытом море ночью - своевременное обнаружение судна цели на удалении 12 миль возможно только с помощью радара. В этом случае маневры курсом для предотвращения чрезмерного сближения с судном целью должны предприниматься по правилам 19 (d), 19 (d) (i) и 19 (d) (ii) до тех пор, когда суда сблизятся на дистанцию видимости топовых огней, обнаружение которых можно ожидать при сближении с судном целью на дистанцию 6 миль в условиях полной метеорологической видимости ( $\tau=0.8$ на милю).

Действия второго этапа для избежания столкновения или для минимизации последствий неизбежного столкновения с судном целью должны предприниматься при сближении с этим судном на дистанцию визуальной видимости знаков или круговых огней, предусмотренных Правилами Части С МППСС-72, когда суда на виду друг у друга или при сближении с судном целью на дистанцию слышимости судового свистка, когда наблюдение за судном целью ведется только с помощью радара, если при этом выявлены признаки угрозы столкновения, предусмотренные Правилом 7 МППСС-72. Необходимость распознавания шаров, конусов и ромбов, а также белых, красных и зеленых круговых огней обусловлена тем, что действия для избежания столкновения судов, находящихся на виду друг у друга, регламентированы Правилами Раздела II Части В МППСС-72, которые определяют взаимные обязанности судов с механическим двигателем, парусных судов и судов, занятых ловом рыбы, а также судов, ограниченных или лишенных возможности управляться, статус которых в контексте МППСС-72 можно определить только с помощью соответствующей комбинации знаков и круговых огней. Ожидаемая дальность видимости круговых огней судна цели согласно Правилу 22 МППСС-72 в диапазоне 2-3 миль при полной метеорологической видимости ( $\tau=0.8$ на милю). Если судно цель в светлое время суток находится на виду, то дальность видимости знаков МППСС72 определяют по формуле:

$$
D=\frac{d}{a r c \gamma^{\prime}}=\frac{0.6 \times 3438}{2}=1031.4 \text { м } \approx 0.5 \text { мили },
$$

где $d$ - диаметр шара, который согласно Приложению I к МППСС-72 должен быть не менее 0.6 метра.

При наблюдении за судном целью с помощью оптических средств дальность видимости знаков МППСС-72 определяют следующим образом:

$$
D_{\text {мили }}=0.5 \mathrm{n},
$$

где $\mathrm{n}$ - кратность оптического средства.

Таким образом, чтобы убедиться в отсутствии знаков МППСС-72 на судне цели и тем самым определить статус этого судна в контексте МППСС-72 как судна с механическим двигателем, необходимо сблизиться с этим судном на дистанцию 0.5 мили, если наблюдение ведется невооруженным глазом, или сблизиться на дистанцию $\mathrm{n} \times 0.5$ миль, если наблюдение ведется с помощью оптических средств с кратностью $\mathrm{n}$.

Дальность слышимости судового свистка зависит от уровня звукового давления, который согласно Приложению III к МППСС-72 должен быть в диапазоне 120-143 дб и обеспечивать слышимость звукового туманного сигнала на расстоянии 0.5-2 мили.

Если при этом наблюдение за судном целью ведется только с помощью радара и к тому же имеют место признаки угрозы столкновения, то действия второго этапа для избежания столкновения или для минимизации последствий неизбежного столкновения регламентированы Правилом 19 (е) МППСС-72, которое предписывает уменьшение скорости хода судна до минимально возможного значения или остановку движения и в любом случае движение с крайней осторожностью. Столь неопределенные действия, единственно возможные в данной ситуации, не придают уверенности в благополучном исходе расхождения с судном целью и поэтому при плавании в открытом море не следует сближаться с судном целью на дистанцию слышимости его звуковых туманных сигналов, если наблюдение за этим судном ведется только с помощью радара. Поскольку в момент принятия решения на выполнение своевременного маневра для предотвращения чрезмерного сближения наблюдение за судном целью в темное время суток ведется только с помощью радара, то чрезмерным сближением при плавании в открытом море ночью следует считать сближение на кратчайшее расстояние 2 мили и менее, если длина судна цели не более 250 м, или 2.5 мили и менее, если длина судна цели в диапазоне 250300 м, или 3 мили и менее, если длина судна цели в диапазоне 350-400 м или неизвестна. 
4.3 Исследование порядка действий для предупреждения столкновения судов в узкости и в системе разделения движения

При плавании в узкости действия первого этапа по предотвращению чрезмерного сближения регламентированы Правилом 9 МППСС-72. Поскольку ширина судоходной зоны в узком проходе ограничена двумя милями по определению и суда в этом проходе движутся двумя встречными потоками, то сближение судов является чрезмерным, если во время расхождения встречных судов на контркурсах или во время обгона возникает поперечная гидродинамическая сила присасывания двух судов. Кроме того, чрезмерное сближение может возникнуть во время пересечения каким-либо судном полосы движения. Поэтому Правило 9 (а) МППСС-72 разделяет встречные потоки судов в узком проходе. Правила 9 (в) и 9 (с) обязывают суда длиной 20 м и менее, а также парусные суда и суда, занятые ловом рыбы, не затруднять движение любого судна, которое может безопасно следовать только в пределах узкого прохода или фарватера. Правило 9 (d) запрещает пересекать узкий проход, если такое пересечение затрудняет движение другого судна, которое следует вдоль этого прохода.

Из теории судна [7] известно, что поперечная гидродинамическая сила присасывания двух судов возникает при взаимном траверзном расстоянии между бортами, равном двум с половиной ширинам меньшего из двух встречных судов $\left(\mathrm{d}_{\mathrm{kp}} \leq 2.5 \mathrm{~B}_{\text {м.с. }}\right)$ и шести ширинам меньшего судна во время обгона $\left(\mathrm{d}_{\mathrm{kp}} \leq\right.$ 6В м.с.). Ширину встречного или обгоняемого судна можно определить с помощью АИС. При отсутствии этой информации - в расчете критического траверзного расстояния между двумя судами принимают ширину собственного судна. С учетом того, что величина поперечной гидродинамической силы присасывания судов прямо пропорциональна скорости движения этих судов, а также просадка судов на мелководье при совместном движении этих судов может увеличиться на $20 \div 50 \%$, то безопасной скоростью при встречном движении и при обгоне следует считать скорость, значение которой вычисляют по методике, изложенной в изданиях $[7,11,12]$ :

- если минимальная глубина на фарватере более трех осадок судна $\left(\mathrm{H}_{\mathrm{f}} \geq 3 \mathrm{~d}\right)$, то безопасную скорость при встречном движении и при обгоне вычисляют по формуле:

$$
V=0.2 \sqrt{g L},
$$

где $g$ - ускорение свободного падения, м/ ${ }^{2}$;

$L$ - длина меньшего судна, м.

- если минимальная глубина моря на фарватере менее трех осадок судна $\left(\mathrm{H}_{\mathrm{f}}<3 \mathrm{~d}\right)$, то безопасную скорость при встречном движении и при обгоне вычисляют по формуле:

$$
V=0.5 V_{\kappa p}=0.5 k \sqrt{g \mathrm{H}_{\mathrm{f}}},
$$

где $k-$ коэффициент, величину которого вычисляют по формуле Ремиша (7) или по формуле Сухомела и Басина (8):

$$
\begin{aligned}
& k=0.22 \sqrt{n_{\kappa}-1} ; \\
& k=\sqrt{8 \cos ^{2}\left[\frac{\pi+\operatorname{arc}\left(1-\frac{1}{n_{\kappa}}\right)}{3}\right]},
\end{aligned}
$$

где $n_{\kappa}-$ коэффициент стесненности фарватера, величину которого вычисляют по формуле:

$$
n_{\kappa}=\frac{\mathrm{B}_{\mathrm{f}} \mathrm{H}_{\mathrm{f}}}{\mathrm{B}_{\mathrm{c}} \mathrm{d}_{\mathrm{c}}},
$$

где $\mathrm{B}_{\mathrm{f}}$ и $\mathrm{H}_{\mathrm{f}}-$ соответственно ширина и глубина фарватера, м;

$\mathrm{B}_{\mathrm{c}}$ и $\mathrm{d}_{\mathrm{c}}-$ соответственно ширина и осадка собственного судна, м.

Коэффициент стесненности фарватера $n_{\kappa}$ является критерием канала [7]:

- если значение $n_{\kappa}$ не превышает $12\left(n_{\kappa} \leq\right.$ 12), то считается, что плавание происходит в канале, обгон в котором согласно требованию обычной морской практики не производится ни при каких обстоятельствах;

- если значение $n_{\kappa}$ более $12\left(n_{\kappa}>12\right)$, то считается, что плавание происходит в узкости, обгон в которой производится в строгом соответствии с Правилом 9 (е) (i) МППСС-72.

Таким образом, при плавании в узкости скорость собственного судна при расхождении с судном на встречных курсах или при обгоне предлагается вычислять в следующей последовательности:

1. Вычисляют коэффициент стесненности фарватера (9).

2. Если $n_{\kappa} \leq 12$, то плавание происходит в канале, в котором обгон запрещен. Скорость судна при расхождении со встречными судами вычисляют по формулам (6) и (7):

$$
\begin{gathered}
V_{y 3}=\frac{0.5 k \sqrt{\mathrm{gH}_{\mathrm{f}}}}{0.514}=0.97 \times 0.22 \sqrt{9.8} \sqrt{\mathrm{H}_{\mathrm{f}}\left(n_{k}-1\right)} \\
V_{y 3}=0.67 \sqrt{\mathrm{H}_{\mathrm{f}}\left(n_{k}-1\right)}
\end{gathered}
$$

3. Если $n_{\kappa}>12$, то плавание происходит в узкости. Если при этом $\mathrm{H}_{\mathrm{f}}<3 \mathrm{~d}_{\mathrm{c}}$, то скорость судна при расхождении со встречными судами и при обгоне вычисляют по формуле (10). Если $\mathrm{H}_{\mathrm{f}}$ $>3 \mathrm{~d}_{\mathrm{c}}$, то скорость судна при расхождении со встречными судами и при обгоне вычисляют по формуле (5): 


$$
V_{y 3}=\frac{0.2 \sqrt{g L}}{0.514}=0.39 \sqrt{9.8} \sqrt{L}=1.22 \sqrt{L}
$$

Исходя из требований хорошей морской практики обгон в узкости не производится, если длина обгоняющего судна в 3 раза больше длины обгоняемого судна. Обгон судна в узкости не производится ни при каких обстоятельствах, если наблюдение за обгоняемым судном ведется только с помощью радара, так как при ограниченной ширине судоходной зоны в узкости - туманный сигнал обгоняемого судна будет услышан впереди траверза и поэтому согласно Правилу 19 (е) МППСС-72 обгоняющее судно обязано уменьшить ход и следовать с крайней осторожностью.

Таким образом, если на каком-либо участке узкого прохода ширина судоходной зоны не позволяет разойтись встречным судам на траверзном расстоянии более 2.5 ширин меньшего судна, то этот участок узкости встречным судам необходимо проходить поочередно. При определении очередности прохода привилегию имеют следующие суда:

$$
\text { Судно, лишенное возможности }
$$

управляться, имеет привилегию перед всеми судами, кроме судна, ограниченного в возможности маневрировать [Правило 18 (d) (i)].

- Судно, ограниченное в возможности маневрировать, имеет привилегию перед всеми судами, кроме судна, лишенного возможности управляться [Правило 18 (d) (i)].

- Судно, стесненное своей осадкой, имеет привилегию перед всеми судами, кроме судна, лишенного возможности управляться, и судна, ограниченного в возможности маневрировать [Правило 18 (d) (i)].

- Судно с механическим двигателем имеет привилегию перед всеми судами, кроме судна с механическим двигателем длиной более 20-ти метров, судна, стесненного своей осадкой, судна, лишенного возможности управляться и судна, ограниченного в возможности маневрировать [Правило 9 (b), 9 (c), 18 (d) (i)].

- Судно, занятое ловом рыбы, имеет привилегию только перед парусным судном [Правило 9 (b), 18 (e)].

- Парусное судно не имеет привилегии ни перед какими-либо судами [Правило 9 (b), 18 (d) (i)].

Если при обгоне ширина судоходной зоны в узкости не позволяет обгоняющему судну пройти на траверзном расстоянии от обгоняемого судна более 6-ти длин меньшего судна, то обгон должен производиться в строгом соответствии с Правилами 9 (е) (i) и 9 (e) (ii).

Поскольку формулы $\mathrm{S}_{\text {без }}>2.5 \mathrm{~B}$ и $\mathrm{S}_{\text {без }}>6 \mathrm{~B}$ определяют безопасное траверзное расстояние расхождения между бортами встречных судов и между бортами обгоняемого и обгоняющего

ISPC Results and Perspectives,

Harrisburg, USA судов, а антенны РЛС на этих судах установлены в диаметральной плоскости или близко к ней, то для практического использования предлагаются следующие формулы: $\mathrm{S}_{\text {без }}>2.5 \times 2 \mathrm{~B} / 185.2=0.03 \mathrm{~B}$ и $\mathrm{S}_{\text {без }}>6 \times 2 \mathrm{~B} / 185.2=0.07 \mathrm{~B}$, где $\mathrm{S}_{\text {без }} \mathrm{B}$ кабельтовых, В - ширина своего судна в метрах.

Исходя из Правила 9 (d) МППСС-72 - судно, пересекающее узкость, должно проходить по корме судна, идущего вдоль узкого прохода, чтобы не затруднить этому судну движение. Если же в ситуации сближения двух судов в узкости обнаружены признаки угрозы столкновения, предусмотренные Правилами 7(d) (i) и 7(d) (i) МППСС-72, то независимо от причин и виновников возникновения ситуации столкновения - действие Правил 9 и 18 (d) (i) МППСС-72 для этих двух судов прекращается и вступают в силу Правила 8(e), 11-17, 18 (a), 18 (b) и 18 (c), которые регламентируют действия второго этапа для избежания столкновения или минимизации последствий неизбежного столкновения, если судно цель на виду и при этом днем различимы его знаки (шары, ромбы, конусы, цилиндры), а ночью видны его бортовые огни или кормовой огонь, а значит должны быть видны круговые белые, красные и зеленые огни, если они установлены на видном месте судна цели. Если наблюдение за судном целью ведется только с помощью радара, то действия второго этапа регламентированы Правилом 19 (е) МППСС-72.

При плавании в системе разделения движения все суда, находящиеся на ходу в полосе движения и за ее пределами, являются потенциально опасными в плане столкновения, так как реальная угроза столкновения может возникнуть при входе, выходе и пересечении полосы движения другими судами, а также во время обгона любого судна или при встрече с судном, занятым ловом рыбы. Поэтому действия первого этапа по предотвращению возникновения ситуации чрезмерного сближения судов при плавании в системе разделения движения регламентированы Правилом 10 МППСС-72, в котором определен порядок входа, выхода и пересечения полосы движения, а также сформулированы требования к судам длиной менее 20 м, парусным судам и судам, занятым ловом рыбы, не затруднять движение судна, идущего в полосе движения. Наиболее безопасной скоростью хода в полосе движения является «скорость потока», равная средней скорости всех судов, идущих в одном направлении в этой полосе. При необходимости обгона - Правило 10 МППСС-72 допускает выход обгоняющего судна за границы полосы движения для расхождения с обгоняемым судном на безопасном расстоянии (на расстоянии более 6-ти ширин меньшего судна). 
При выявлении признаков угрозы столкновения с каким-либо судном в полосе движения, предусмотренных Правилами 7 (d) (i) и 7 (d) (ii) МППСС-72 - независимо от причин и виновников возникновения ситуации столкновения - действие Правила 10 МППСС-72 по первому этапу предупреждения столкновения для этих двух судов прекращается и вступают в силу Правила 8 (e), 11-17, 18 (a), 18 (b) и 18 (c) по действиям второго этапа для избежания столкновения или для минимизации последствий неизбежного столкновения, если суда на виду друг у друга, или Правила 8 (е) и 19 (е), если наблюдение за судном целью ведется только с помощью радара.

5. Выработка алгоритма действий для предупреждения столкновения судов

Поскольку исходные данные для выработки алгоритма действий по безопасному расхождению судов зависят от степени стесненности района плавания, то предлагается на стадии планирования рейса маршрут перехода разделить на следующие участки с учетом коэффициента стесненности района плавания $n_{\kappa}$ (9):

- канал, если $n_{\kappa}<12$;

- узкость, если $n_{\kappa}>12$ и при этом ширина судоходной зоны менее 2-х миль;

- район плавания с достаточным для маневра курсом водным пространством (район открытого моря в контексте МППСС-72), если $n_{\kappa}>$ 12 и при этом ширина судоходной зоны более $2-\mathrm{x}$ миль.

Алгоритм действий первого этапа при плавании в канале вырабатывается с учетом положений Правила 9 МППСС-72 при выполнении одного условия: обгон в канале не допускается ни при каких обстоятельствах. Таким образом, для предотвращения чрезмерного сближения с встречными судами при плавании в канале предлагается следующие действия первого этапа:

1. При плавании в канале с односторонним движением или если в канале с двухсторонним движением нет встречных судов - идти строго по оси канала.

2. При появлении встречного судна сместиться вправо от оси канала по ходу движения так, чтобы кратчайшее расстояние до бровки (кромки) канала в кабельтовых было не менее, чем $\mathrm{S}=0.03 \mathrm{~B}$, где $\mathrm{B}-$ ширина собственного судна в метрах, так как гидродинамическая сила присасывания возникает не только между бортами встречных судов, но и между бортом и бровкой (кромкой) канала.
3. Предлагаются следующие действия по обеспечению безопасности плавания в канале:

3.1 Установить справа и слева от линии отметки курса на индикаторе радара ограждающие линии параллельной индексации на удалении $\mathrm{S}_{\text {кб }}=0.03 \mathrm{~B}$.

3.2 Скорость хода в канале в узлах не должна превышать значения $V_{y 3}=0.67 \sqrt{\mathrm{H}_{\mathrm{f}}\left(n_{k}-1\right)}$, где $\mathrm{H}_{\mathrm{f}}-$ минимальная глубина канала в метрах.

3.3 Если линия параллельной индексации касается бровки (кромки) канала или эхо-сигнал встречного судна находится на ограждающей линии параллельной индексации или между этой линией и линией отметки курса - необходимо уменьшить скорость хода до минимально возможного значения.

3.4 При пересечении канала курсы встречных судов должны пересекаться по корме этих судов. Если поток встречных судов непрерывный, то пересечение по корме ближайшего встречного судна возможно таким образом, чтобы не затруднять движение остальным встречным судам, то есть не вынуждать эти суда уменьшать скорость хода.

3.5 Лов рыбы в канале не допускается.

3.6 Движение парусных судов в канале допускается только с применением механической силовой установки.

Если при сближении с другим судном возникают признаки столкновения, предусмотренные Правилами 7 (d) (i) и 7 (d) (ii) МППСС-72, то для этих двух судов вступают в действие Правила 8 (e), 11-17, 18 (a), 18 (b), 18 (c) и 19 (е), которые определяют взаимные обязанности этих судов по избежанию столкновения или минимизации последствий неизбежного столкновения в зависимости от категории этих судов согласно Правилу 3 МППСС-72, а также от условий сближения и состояния видимости в канале:

- при полной видимости ( $\tau=0.8$ на милю), когда суда на виду друг у друга - действия судов для избежания столкновения регламентированы Правилами 8 (e), 11-17, 18 (a), 18 (b) и 18 (c);

- при ограниченной видимости, когда наблюдение за судном целью ведется только с помощью радара, действия судов для избежания столкновения регламентированы Правилом 19 (e).

Если район плавания оценивается как узкость, в которой система разделения движения не установлена, то алгоритм действий первого этапа для предотвращения чрезмерного сближения судов в этой узкости вырабатывается в строгом соответствии с требованиями Правила 9 МППСС-72. Основным требованием Правила 9 является необходимость держаться внешней 
границы узкого прохода, которая находится с правого борта судна настолько близко, насколько это безопасно и практически возможно. При этом запас воды под килем $(\Delta \mathrm{H})$ должен быть не менее $1.3 \mathrm{~d}(\Delta \mathrm{H} \geq 1.3 \mathrm{~d})$. Поэтому для обеспечения навигационной безопасности плавания в узкости необходимо провести опасную изобату в виде красной линии, соединяющей глубины $\mathrm{H}=\mathrm{d}+$ $\Delta \mathrm{H}=\mathrm{d}+1.3 \mathrm{~d}$. Для обеспечения навигационной безопасности и безопасности расхождения с встречными и обгоняемыми судами в узкости целесообразно так же, как и при плавании в канале, установить 2 ограждающие линии параллельной индексации справа и слева от линии отметки курса на удалении $\mathrm{S}_{\text {кб }}=0.03 \mathrm{~B}$. При этом:

1. Во время движения вдоль узкого прохода ограждающая линия параллельной индексации не должна касаться опасной изобаты $\mathrm{H}=\mathrm{d}+1.3 \mathrm{~d}$ и тем более пересекать ее.

2. Эхо-сигнал встречных судов не должен находиться на ограждающей линии параллельной индексации или в полосе между этой линией и линией отметки курса. В противном случае необходимо уменьшать скорость хода до минимально-возможного значения.

3. При обгоне, который в узкости может производиться только в условиях полной видимости ( $\tau=0.8$ на милю), когда обгоняемое судно на виду, эхо-сигнал обгоняемого судна не должен находиться на ограждающей линии или в полосе, заключенной между этой линией и линией отметки курса. В противном случае обгон должен производиться в строгом соответствии с Правилами 9 (e) (i), 9 (e) (ii), 34 (c) (i), 34 (c) (ii) и 34 (d) МППСС-72.

4. Обгон в узкости не производится ни при каких обстоятельствах, если длина обгоняющего судна в 3 раза больше длины обгоняемого судна.

5. Скорость хода судна при расхождении с встречными судами или при обгоне не должна превышать следующих значений:

$$
-V_{y 3} \leq 1.22 \sqrt{L}
$$

где $L$ - длина собственного судна в метрах, если минимальная глубина моря на фарватере более 3х осадок судна $\left(\mathrm{H}_{\mathrm{f}}>3 \mathrm{~d}\right)$;

$$
-V_{y_{3}} \leq 0.67 \sqrt{\mathrm{H}_{\mathrm{f}}\left(n_{k}-1\right)},
$$

если минимальная глубина моря на фарватере менее трех осадок судна $\left(\mathrm{H}_{\mathrm{f}}<3 \mathrm{~d}\right)$.

Порядок пересечения узкости должен быть аналогичен порядку пересечения канала.

Суда длиной менее 20 метров, парусные суда и суда, занятые ловом рыбы, не должны затруднять движение любому судну, следующему в пределах узкого прохода или фарватера. Однако, если в нарушение Правил 9 (b) и 9 (c) действие парусного судна или судна, занятого ловом рыбы, приводят к возникновению угрозы столкновения с судном с механическим двигателем, то это парусное судно или это судно, занятое ловом рыбы, не является автоматически виновником столкновения, так как при возникновении ситуации столкновения между двумя судами - действие Правила 9 для этих судов прекращается и вступает в силу Правило 18 (a), согласно которому судно с механическим двигателем обязано уступить дорогу парусному судну или судну занятому ловом рыбы, ибо с момента возникновения угрозы столкновения любых двух судов - действия первого этапа для предотвращения чрезмерного сближения этих судов прекращаются и начитаются действия второго этапа для избежания столкновения.

При плавании в системе разделения движения действия первого этапа для предотвращения чрезмерного сближения судов регламентированы Правилом 10 МППСС-72. Поскольку развитие ситуации чрезмерного сближения возможно при обгоне и даже при встречном движении судов на контркурсах в случае ошибочного захода судна не в свою полосу движения, то алгоритм действий первого и второго этапов для предупреждения столкновения при плавании в системе разделения движения аналогичен алгоритму действий для предупреждения столкновения при плавании в узкости, особенно, если система разделения движения установлена в узком проходе.

Если система разделения установлена в зоне интенсивного судоходства района открытого моря, то для безопасного расхождения судов во время обгона - Правила 10 (d) (ii) и 10 (e) (ii) допускают выход обгоняющего судна в зону прибрежного плавания и в зону разделения движения.

При плавании в районе с достаточным для маневрирования курсом водным пространством (в районе открытого моря в контексте МППСС72) вне границ системы разделения движения судно не должно допускать сближение с любым другим судном на дистанцию чрезмерного сближения, которая в зависимости от времени суток и метеорологической видимости в районе плавания может иметь следующие значения:

1. $\mathrm{D}_{\text {кр }} \leq 1$ миля в светлое время суток, если судно цель длиной 20-50 метров находится на виду.

2. $\mathrm{D}_{\text {кр }} \leq 1.5$ миль в светлое время суток, если судно цель длиной 50-150 метров находится на виду.

3. $\mathrm{D}_{\text {кр }} \leq 2$ миль, если:

3.1 В светлое время суток судно цель длиной 150-250 метров находится на виду.

3.2 Наблюдение за судном целью длиной менее 250 метров ведется только с помощью радара. 
4. $\mathrm{D}_{\text {кр }} \leq 2.5$ миль, если длина судна цели в диапазоне 250-350 метров при любых условиях видимости.

5. $\mathrm{D}_{\text {кр }} \leq 3$ миль, если длина судна цели в диапазоне 350-400 метров при любых условиях видимости.

Предлагается следующий алгоритм действий первого этапа для предотвращения чрезмерного сближения судов в открытом море:

1. В целях выполнения требования Правила 8 (а) МППСС-72 о своевременных и уверенных действия, предпринимаемых для предотвращения чрезмерного сближения с судном целью - внешнюю границу зоны автоматического захвата судна цели на автосопровождение необходимо установить на удалении 12 миль, на которой погрешность измерения полярных координат судна цели допустима для вычисления условий расхождения и параметров истинного движения судна цели с достаточной точностью. При этом:

1.1 Для автозахвата обгоняющих судов сектор зоны автоматического захвата судна цели должен быть круговым, если скорость собственного судна менее 25-ти узлов. При наличии теневых секторов на развертке ИКО необходимо систематически изменять курс на $15^{\circ}-20^{\circ}$ для освещения этих теневых секторов.

1.2 Если скорость собственного судна 25 узлов и более - сектор зоны автоматического захвата судна цели целесообразно установить в диапазоне $120^{\circ}$ л/б $-0^{\circ}-120^{\circ}$ пр/б.

2. Основное наблюдение необходимо вести на шкале дальности 12 миль и более с периодическим кратковременным переключением на шкалы дальности 2-3 мили для своевременного обнаружения малозаметных целей с незначительной площадью эффективного радиолокационного отражения.

3. При срабатывании визуальной и звуковой сигнализации оповещения о захвате судна цели на автоматическое сопровождение предлагаются следующие действия вахтенного офицера:

3.1 Убедиться в том, что судно цель находится на устойчивом автосопровождении в течение трех минут.

3.2 Установить подвижный круг дальности на удалении 1 миля или 1.5 мили или 2 мили или 2.5 мили или 3 мили в зависимости от времени суток, условий видимости и длины судна цели и зафиксировать окружность этого круга.

3.3 Если ЛОД судна цели после устойчивого трехминутного автосопровождения проходит по касательной к окружности зафиксированного круга дальности или пересекает эту окружность, то предпочтительный маневр курсом для увеличения дистанции кратчайшего сближения с этим судном необходимо производить следующим образом:
3.3.1 Если в момент принятия решения на маневр судно цель находится на виду, то изменение курса Правилами ПСС не регламентировано.

3.3.2 Если в момент принятия решения на маневр наблюдение за судном целью ведется только с помощью радара, то маневр курсом для увеличения дистанции кратчайшего сближения регламентирован правилом 19 (d) МППСС-72, согласно которому следует по возможности избегать изменение курса влево, если судно цель находится впереди траверза и не является обгоняемым, а также следует по возможности избегать изменение курса в сторону судна цели, если это судно находится на траверзе или позади траверза. Таким образом, отступление от Правила 9 (d) допускается при определенных обстоятельствах, которые должны быть достаточно обоснованными для признания правомерности этого отступления. Таким обоснованием может быть развитие ситуации чрезмерного сближения или ситуации столкновения с другим судном при имитации маневра курсом согласно Правилу 9 (d), но только в том случае, если имитация маневра скоростью не обеспечивает безопасное расхождение с судном целью и другими судами.

4. Если по какой-либо причине чрезмерное сближение с судном целью предотвратить не удалось и на расстоянии визуальной видимости знаков и круговых огней судна цели, предусмотренных Правилами Части С МППСС72 при полной метеорологической видимости или на расстоянии слышимости звуковых туманных сигналов судна цели при ограниченной видимости выявляются признаки столкновения, предусмотренные Правилом 7 МППСС-72, то необходимо предпринять действия второго этапа для избежания столкновения, регламентированные Правилами 8 (c), 11-17, 18 (a), 18 (b) и 18 (e), если судно цель на виду, или Правилом 19 (е), если наблюдение за судном целью ведется только с помощью радара.

\section{6. Выводы}

В статье впервые рассмотрены следующие аспекты безопасности мореплавания в контексте МППСС-72:

1. Мотивация количественных и качественных характеристик таких понятий, как узкость, достаточное для маневрирования курсом водное пространство, чрезмерное сближение судов, расхождение судов на безопасном расстоянии, своевременные и уверенные действия для предупреждения столкновения судов, что позволяет определять диапазон исходных данных, в пределах которых возможна выработка алгоритма действий для оперативного 


\begin{tabular}{l|lr|ll|ll} 
& ISRA (India) & $=\mathbf{1 . 3 4 4}$ & SIS (USA) & $=\mathbf{0 . 9 1 2}$ & ICV (Poland) & $=\mathbf{6 . 6 3 0}$ \\
Impact Factor: & ISI (Dubai, UAE) $=\mathbf{0 . 8 2 9}$ & PUHIL (Russia) $=\mathbf{0 . 2 3 4}$ & PIF (India) & $=\mathbf{1 . 9 4 0}$ \\
& GIF (Australia) & $\mathbf{0 . 5 6 4}$ & ESJI (KZ) & $=\mathbf{1 . 0 4 2}$ & IBI (India) & $\mathbf{= 4 . 2 6 0}$ \\
& JIF & $=\mathbf{1 . 5 0 0}$ & SJIF (Morocco) & $=\mathbf{2 . 0 3 1}$ & & \\
\hline
\end{tabular}

принятия решения на маневр по безопасному расхождению судов.

2. Вероятностный подход к оценке угрозы столкновения судов, что позволяет разделить действия для предупреждения столкновения на 2 этапа с целью упорядочения применения Правил ПСС для принятия решения на маневр по безопасному расхождению судов:

2.1 Действия первого этапа для предотвращения чрезмерного сближения судов при потенциальной и реальной угрозах столкновения, регламентируемые Правилами 8, 9,
10 Раздела I, Правилами 18 (d) (i), 18 (d) (ii) и 18 (e) Раздела II, Правилами 19 (a), 19 (b), 19 (c) и 19 (d), 19 (d) (i) и 19 (d) (ii) Раздела III Части В МППСС-72.

2.2 Действия второго этапа для избежания прямого столкновения или для минимизации последствий неизбежного столкновения, регламентируемые Правилом 8 (е) Раздела I, Правилами 11-17, 18 (a), 18 (b) и 18 (c) Раздела II, а также Правилом 19 (е) Раздела III Части В МППСС-72.

\section{References:}

1. Demirel E, Bayer D (2015) Further studies on the COLREGs (Collision Regulations) // The International Journal on Marine Navigation and Safety of Sea Transportation. - Gdynia, Poland. 9 (1) 2015, - pp. 17-23.

2. Đani Mohović (2015) Identifying skill gaps in the knowledge and teaching of COLREGs / Đani Mohović, Robert Mohović, Mate Barić // 17th International Conference on Transport Science - ICTS 2015. - Rijeka, Croatia. - pp. 339-348.

3. Najdenov E (2014) Neobxodimy' novy'e MPPSS // Morskie vesti Rossii. - 2014. №13., pp. 14-16.

4. (2004) Convention on the International Regulations for Preventing Collisions at Sea, 1972: consolidated edition 2003. - London: IMO, $2004-53$ p.

5. Sharlaj GN (2015) MPPSS-72 s kommentariyami [Tekst]: uchebnoe posobie / G.N. Sharlaj. - Vladivostok: Mor. gos. un-t, 2015. - 134 p.

6. Kokkroft AN, Lameer D (2005) N.F. Rukovodstvo po Pravilam preduprezhdeniya stolknoveniya (MPPSS-72) / 9A.N. Kokkroft, Dzh. N.F. Lameer.; per. s angl. Shajxutdinova N.T. i Shhigoleva K.V. - SPb.: OOO «MORSAR», 2005. -320 p.
7. Snopkov VI (2004) Upravlenie sudnom: uchebnik dlya vuzov / V.I. Snopkov. - [3-e izd.]. - SPb.: ANO NPO «Professional», 2004. $-536 \mathrm{p}$.

8. Sharlay GN (2013) Upravlenie morskim sudnom [Tekst]: uchebnoe posobie / G.N. Sharlay. - Vladivostok: Mor. gos. un-t, 2013. $578 \mathrm{p}$.

9. (2004) Bezopasnost' zhiznedeyatel'nosti: uchebnik dlya vuzov / Belov S. V., Devisilov V. A., Il'nickaya A. V. [i dr.] ; red. Belov S. V. - 4-e izd., ispr. i dop. - M. : Vy'ssh. shk., 2004. $605 \mathrm{p}$.

10. (2015) Bezopasnost' zhiznedeyatel'nosti i zashhita okruzhayushhej sredy' (texnosfernaya bezopasnost'): uchebnik dlya akademicheskogo bakalavriata / Belov S. V. - 5-e izd., pererab. i dop. - M. : Yurajt : ID Yurajt, 2015. - 701 p.

11. Vagushhenko LL (2002) Sistemy' avtomaticheskogo upravleniya dvizheniem sudna / L. L. Vagushhenko, N.N. Cy'mbal. - [2e izd.]. - Odessa: LATSTAR, 2002. - 310 p.

12. Vagushhenko LL (2007) Sistemy' avtomaticheskogo upravleniya dvizheniem sudna / L. L. Vagushhenko, N.N. Cy'mbal. - [3e izd.]. - Odessa: Feniks, 2007. - 328 p. 